\title{
Dirgamaya
}

\author{
Jurnal Manajemen dan Sistem Informasi
}

Accepted Date : 10 - 11 - 2021, Publish Date : 13 - 11 - 2021 Vol 01. Issue 02

\section{Pemodelan Proses Bisnis Pendaftaran Rawat Inap pada Rumah Sakit Dewi Sri Karawang menggunakan Business Process Modeling Notation (BPMN)}

\author{
Muhamad Jafar Ali Hamzah ${ }^{\text {a*}}$, Rizki Narezka Hariyanto ${ }^{\mathrm{b}}$ \\ ${ }^{a, b}$ STMIK Rosma, Jl. Kertabumi No. 62, Karawang 41311, Indonesia \\ *Corresponding author: muhamad.hamzah@mhs.rosma.ac.id
}

\begin{abstract}
Business processes are the core of all activities in a company or organization. This study aims to model the inpatient registration business process at Dewi Sri Hospital by using the Business Process Modeling Notation (BPMN) to obtain a business model that is easily understood by all parties involved in the process. This study uses data collection methods with stages: interviews, literature study, problem analysis and business process modeling. The results of this study are business process modeling on inpatient registration which is expected to provide benefits to Dewi Sri Hospital management for innovation and company competitive advantage.
\end{abstract}

Keywords : Business Processes, Business Process Modeling Notation (BPMN), Inpatient Registration

\begin{abstract}
Abstrak
Proses Bisnis merupakan inti dari seluruh aktivitas yang ada didalam perusahaan atau organisasi. Penelitian ini bertujuan untuk memodelkan proses bisnis pendaftaran rawat inap pada Rumah Sakit Dewi Sri dengan menggunakan Business Process Modeling Notation (BPMN) untuk mendapatkan model bisnis yang mudah dimengerti oleh semua pihak yang terlibat dalam proses tersebut. Penelitian ini menggunakan etode pengumpulan data dengan tahapan: wawancara, studi literatur, analisis masalah dan pemodelan proses bisnis. Hasil penelitian ini berupa pemodelan proses bisnis pada pendaftaran rawat inap yang diharapkan dapat memberikan maanfaat pada manajemen Rumah Sakit Dewi Sri untuk inovasi dan keunggulan kompetitif perusahaan.
\end{abstract}

Kata Kunci : Proses Bisnis, Business Process Modeling Notation (BPMN), Pendaftaran Rawat Inap

\section{Pendahuluan}

Kemajuan teknologi informasi membantu meningkatkan efisiensi proses bisnis. Proses bisnis digunakan oleh organisasi nirlaba (non-profit) serta organisasi atau perusahaan komersial. Organisasi nirlaba perlu mengembangkan dan meningkatkan proses bisnis mereka karena organisasi nirlaba memiliki beberapa persyaratan, seperti mencapai tujuan yang telah ditentukan, produktivitas dan efisiensi terhadap semua manajemen dalam organisasi. Proses bisnis adalah serangkaian aktivitas yang saling terkait yang dilakukan secara berurutan atau paralel oleh orang-orang atau sistem di dalam dan di luar organisasi untuk mencapai tujuan bisnis tertentu. Menurut Hammer dan Champy (tahun 1994, p35) didalam (Ramdhani, 2015) Proses bisnis merupakan sekumpulan aktivitas yang memerlukan satu atau lebih masukan / input dan membentuk suatu keluaran / output yang memiliki nilai yang diinginkan pelanggan. Analisa proses bisnis umumnya melibatkan pemetaan proses dan subproses di dalamnya hingga tingkatan aktivitas atau kegiatan. Analisa tersebut dapat dilakukan melalui pemodelan proses bisnis yang menggambarkan cara orangorang atau pihak-pihak saling berinteraksi di dalam sistem, dan dijelaskan dengan cara atau standar tertentu (Dewi et al., n.d.). 
Rumah Sakit Dewi Sri (RSDS) merupakan perusahaan dibidang pelayanan kesehatan, saat ini perusahaan tersebut belum memiliki inisiasi pengelolaan proses bisnis, selama melakukan penelitian, peneliti melakukan wawancara semi-terstruktur dengan pegawai rumah sakit. Beberapa penelitian terdahulu seperti yang dilakukan oleh (Yunitarini \& Hastarita, 2016), (Setiyani et al., 2021), (Rifai et al., 2021) yang melakukan pemodelan proses bisnis menggunakan Business Process Modelling Notation (BPMN), sehingga peneliti tertarik untuk memodelkan proses bisnis pendaftaran rawat inap RS Dewi Sri menggunakan BPMN. BPMN adalah representasi grafis untuk menentukan proses bisnis dalam suatu pemodelan proses bisnis.Tujuan utama dari BPMN adalah menyediakan suatu notasi standar yang mudah dipahami oleh semua pemangku kepentingan bisnis (Lestari et al., 2019). Berdasarkan hal tersebut peneliti memanfaatkan pemodelan proses bisnis pendaftaran rawat inap Rumah Sakit Dewi Sri (RSDS) untuk mendefinisikan dan menginisiasi manajemen proses bisnis dalam rangka perbaikan dan penyempurnaan proses bisnis untuk inovasi atau keunggulan kompetitif perusahaan.

\section{Tinjauan Pustaka}

\subsection{Business Process Management}

Menurut Mathias weske dalam bukunya Business Process Management Concepts, Languages, Architectures tahun 2012, proses bisnis adalah sebuah kumpulan aktivitas yang dijalankan secara koordinasi didalam lingkungan organisasional dan lingkungan teknis. Aktivitas-aktivitas ini bersama-sama mencapai tujuan bisnis. Setiap proses bisnis ditetapkan oleh satu organisasi (bagian), namun dapat berinteraksi dengan proses yang dijalankan organisasi (bagian) lain (Helmi et al., 2018). Business Process Management (BPM) adalah seni dan ilmu untuk mengawasi cara kerja yang dilakukan dalam organisasi untuk memastikan hasil yang konsistem dan memanfaatkan peluang peningkatan/perbaikan (Leopold, 2013). Bussiness Process Management Life Cycle ini terbagi menjadi beberapa tahapan yang diantaranya adalah Process Identification, Process Discovery, Process Analyze, Process Redesign, Process Implementation, Process Monitoting and Controling (Saputra et al., 2020). Process Discovery atau penemuan proses adalah tahap pemodelan proses bisnis yang sedang berlangsung. Pada tahapan ini, keadaan saat ini dari masingmasing proses yang relevan didokumentasikan, biasanya dalam bentuk satu atau beberapa model proses (Vergidis, Tiwari, \& Majeed, 2007) didalam (Saputra et al., 2020).

\subsection{Business Process Modeling Notation (BPMN)}

Business Process Model and Notation atau BPMN merupakan sebuah standar untuk pemodelan proses bisnis yang menyediakan notasi grafis untuk menentukan proses bisnis dalam Diagram Proses Bisnis, yang didasarkan pada teknik flowchart yang juga sangat mirip dengan diagram aktivitas dan Unified Modelling Language (UML). Adapun tujuan dari BPMN ini adalah untuk mendukung manajemen proses bisnis, baik untuk pengguna teknis dan pengguna bisnis, dengan menyediakan notasi yang intuitif untuk pengguna bisnis, namun dapat mewakili proses yang kompleks (Wagiu, 2018).

Tujuan dari BPMN adalah menyediakan notasi yang mudah dipahami oleh semua pengguna bisnis dan yang tidak kalah pentingnya adalah untuk memastikan bahwa bahasa XML yang dirancang untuk pelaksanaan proses bisnis dapat dinyatakan secara visual dengan notasi yang umum (Owen \& Raj, 2003).

\subsection{Elemen $B P M N$}

Diagram BPMN terdiri atas elemen. Elemen ini terbagi atas empat kategori, yaitu Flow Object, Connecting Object, Swimlanes, dan Artifact. Berikut penjelasan dari masing masing elemen BPMN (Setiawan et al., 2019).

\section{a. Flow Object}

1) Event direpresentasikan dalam bentuk lingkaran dan menjelaskan apa yang terjadi saat itu. Ada tiga jenis event, yaitu start, intermediate, dan end. Event-event ini mempengaruhi alur proses alur proses dan biasanya menyebabkan terjadinya kejadian (trigger) atau sebuah dampak (result). Masingmasing mewakili kejadian dimulainya proses bisnis, interupsi proses bisnis, dan akhir dari proses bisnis. Untuk setiap jenis event tersebut sendiri terbagi atas beberapa jenis, misalnya message start, yang dilambangkan seperti start event namun mendapatkan tambahan lambang amplop di dalamnya, yang berarti ada pesan event tersebut dimulai dengan masuknya pesan. 


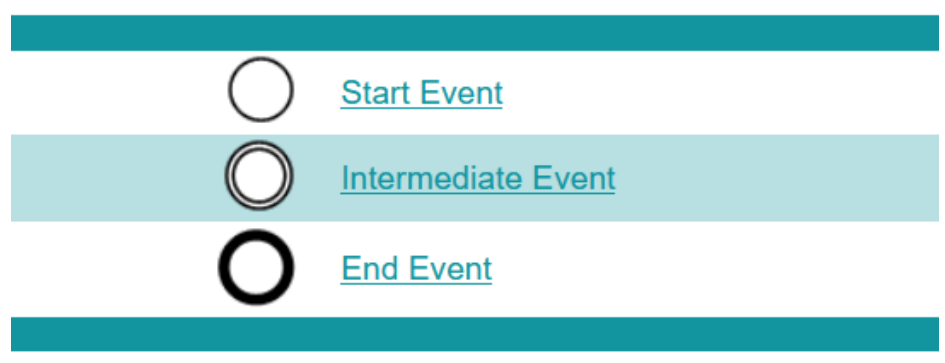

Gambar 2.1 Elemen Event

Sumber: (www.bpmn.org, 2020)

2) Activity merepresentasikan pekerjaan (task) yang harus diselesaikan. Ada tiga macam activity, yaitu task, sub process dan call activity.

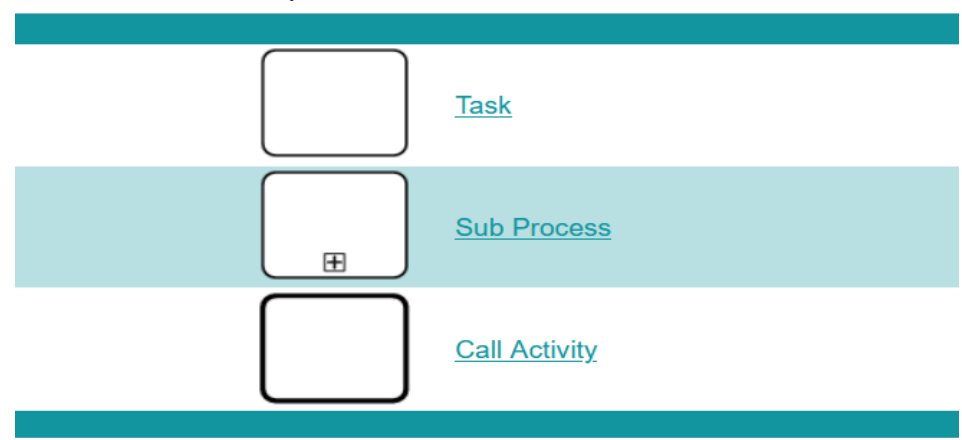

Gambar 2.2 Elemen Activity

Sumber: (www.bpmn.org, 2020)

b. Connecting Object

Connecting object merupakan aliran pesan antar proses dimana satu kejadian dengan kejadian yang lain saling berhubungan dan merepresentasikan dari hubungan tersebut. Adapun simbol-simbol atau gambar dalam penulisan connecting object ada 4 jenis yaitu sequence flow, message flow, association dan data association.

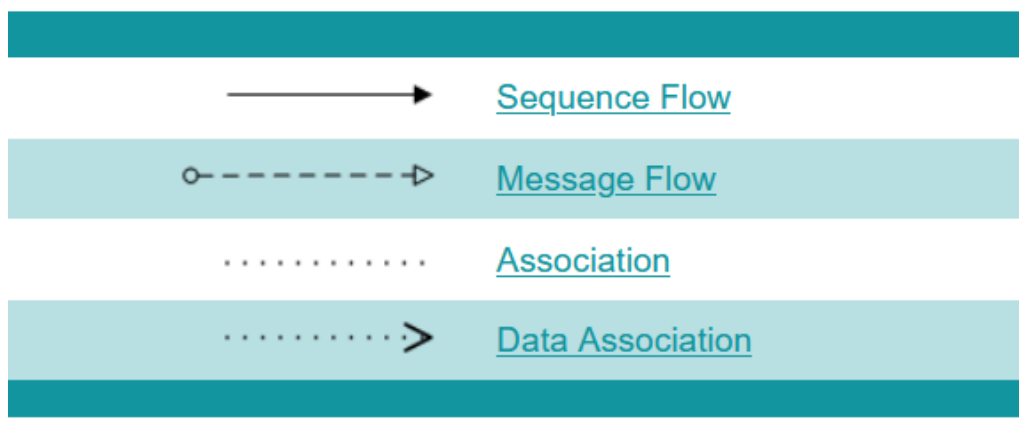

Gambar 2.3 Elemen Connecting Object

Sumber: (www.bpmn.org, 2020)

c. Swimlanes

Elemen ini digunakan untuk mengkategorikan secara visual seluruh elemen dalam diagram. Ada dua jenis swimlanes, yaitu pool dan lane. Perbedaannya adalah lane terletak di bagian dalam pool untuk mengkategorisasi elemen-elemen di dalam pool menjadi lebih spesifik. 


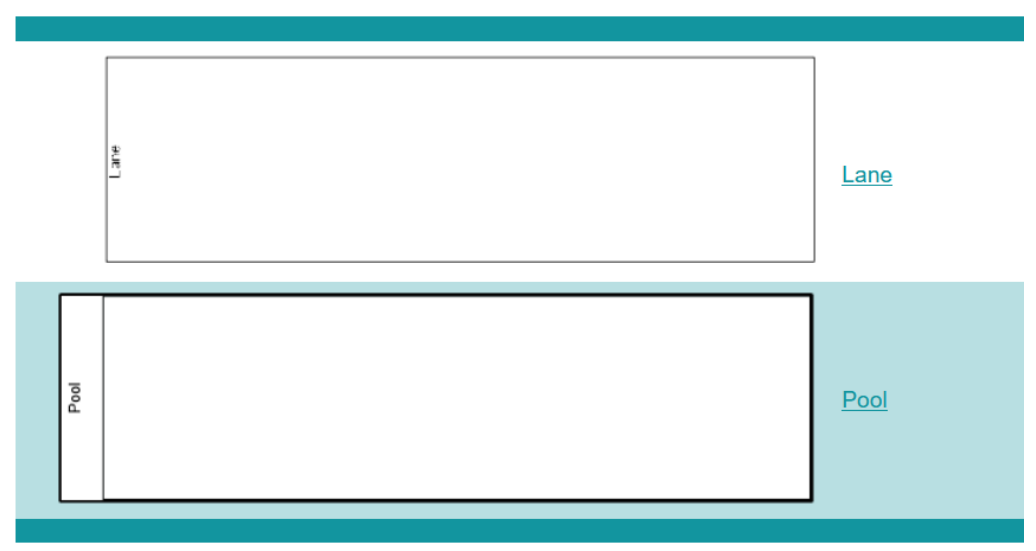

Gambar 2.4 Elemen Swinlanes

Sumber: (www.bpmn.org, 2020)

d. Artifact

Elemen ini digunakan untuk memberi penjelasan di diagram. Elemen ini terdiri atas group dan text annotation.

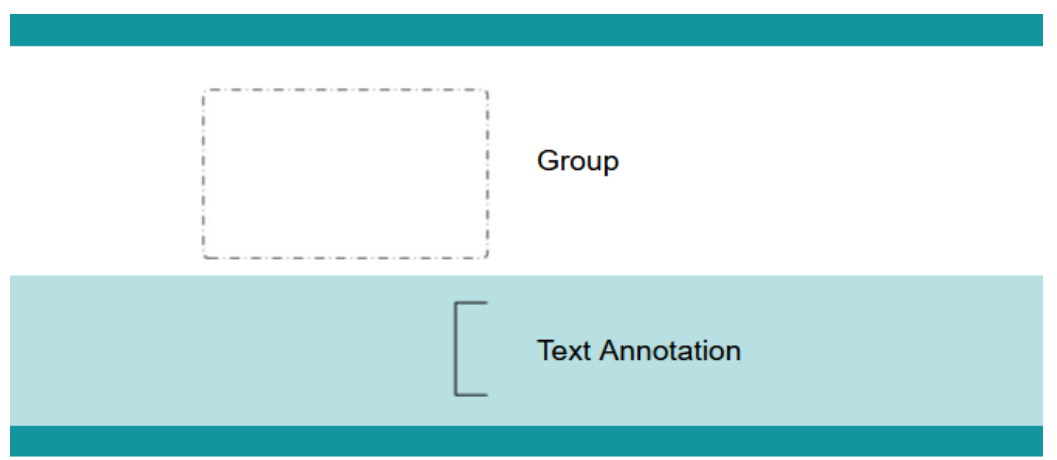

Gambar 2.5 Elemen Artifact

Sumber: (www.bpmn.org, 2020)

\section{Metode}

Adapun metode dalam penelitian ini adalah sebagai berikut.

a. Pengumpulan Data

Pengumpulan data merupakan tahap yang sangat penting dalam sebuah penelitian, data-data tersebut yang terkumpul merupakan bahan utama yang menjadi inti dari objek penelitian (Handayani et al., 2018). Data penelitian berasal dari berbagai sumber informasi seperti dokumen proses bisnis dan wawancara hasil observasi kepada pihak-pihak terkait dengan bagian pendaftaran rawat inap di Rumah Sakit Dewi Sri.

b. Studi Literatur

Pada tahap ini dilakukan pengamatan dan studi literatur guna untuk mendapatkan informasi yang digunakan sebagai data awal (Galih Mardika \& Kartadie, 2019). Studi literatur dilaksanakan dengan cara mengumpulkan dan mempelajari referensi melalui buku dan internet mengenai Proses bisnis dan BPMN.

c. Analisis Masalah

Pada bagian ini, dilakukan analisis masalah berdasarkan hasil analisis domain studi kasus yang mengacu pada proses bisnis akademis Prodi.

d. Pemodelan Proses Bisnis menggunakan BPMN

Pada tahap ini dilakukan pemodelan berdasarkan hasil pengumpulan data dan analisis menggunakan BPMN.

\section{Hasil dan Pembahasan}

\subsection{Deskripsi Sistem}

Berdasarkan hasil pengumpulan data yang telah dilakukan, pada RS Dewi Sri jika pasien akan mendaftar rawat inap dimulai pasien datang ke admission membawa berkas permohonan rawat inap (CM4) dari IGD 
ataupun dari POLI, lalu dilakukan pengecekan data pribadi pasien yang selanjutnya admission melakukan pengecekan ketersedian ruangan sesuai diagnose dan penggunaan jenis jaminan, pada pengecekan ketersedian ruangan apabila ruangan itu tidak tersedia maka admission memberikan konfirmasi ke bagian IGD atau POLI bahwa ruangan pasien tidak tersedia, sedangkan pada pengecekan penggunaan jenis jaminan pasien tersebut menggunakan jenis jaminan apa, apakah datang sebagai pasien umum atau menggunakan jenis jaminan lain seperti jaminan perusahaan, asuransi, BPJS, atau karawang sehat. Jika ruangan sudah tersedia dan pasien sudah menentukan akan menggunakan jaminan apa, selanjutnya admission memberikan konfirmasi kepada perawat bahwa akan ada pasien masuk dengan keterangan pasien tersebut akan di tempatkan di ruangan mana, selanjutnya pasien melakukan pengisian berkas general consent (CM5a) dan setelah itu admission melakukan penginputan general consent dan data diri pasien di aplikasi Z Care.

1. Aktor yang terlibat pada transaksi pendaftaran adalah admission, pasien, dan perawat.

2. Dokumen yang terlibat pada transaksi pendaftaran adalah Permohonan rawat inap (CM4),

General consent (CM5a), Ringkasan masuk dan keluar (CM6), Surat pernyataan perubahan ruang perawatan, Akad perjanjian Ijarah, Visite tindakan dan penunjang medis (CM21).

Berdasarkan hasil pengumpulan data dapat diidentifikasi bahwa pada proses transaksi pendaftaran rawat inap terdapat beberapa sub proses diantaranya penggunaan jaminan BPJS, Asuransi, Perusahaan, dan Karawang Sehat.

\subsection{Pemodelan}

Setelah mendeskripsikan sistem yang ada, kemudian dilakukan pemodelan proses transaksi pendaftaran rawat inap menggunakan BPMN sebagai berikut:

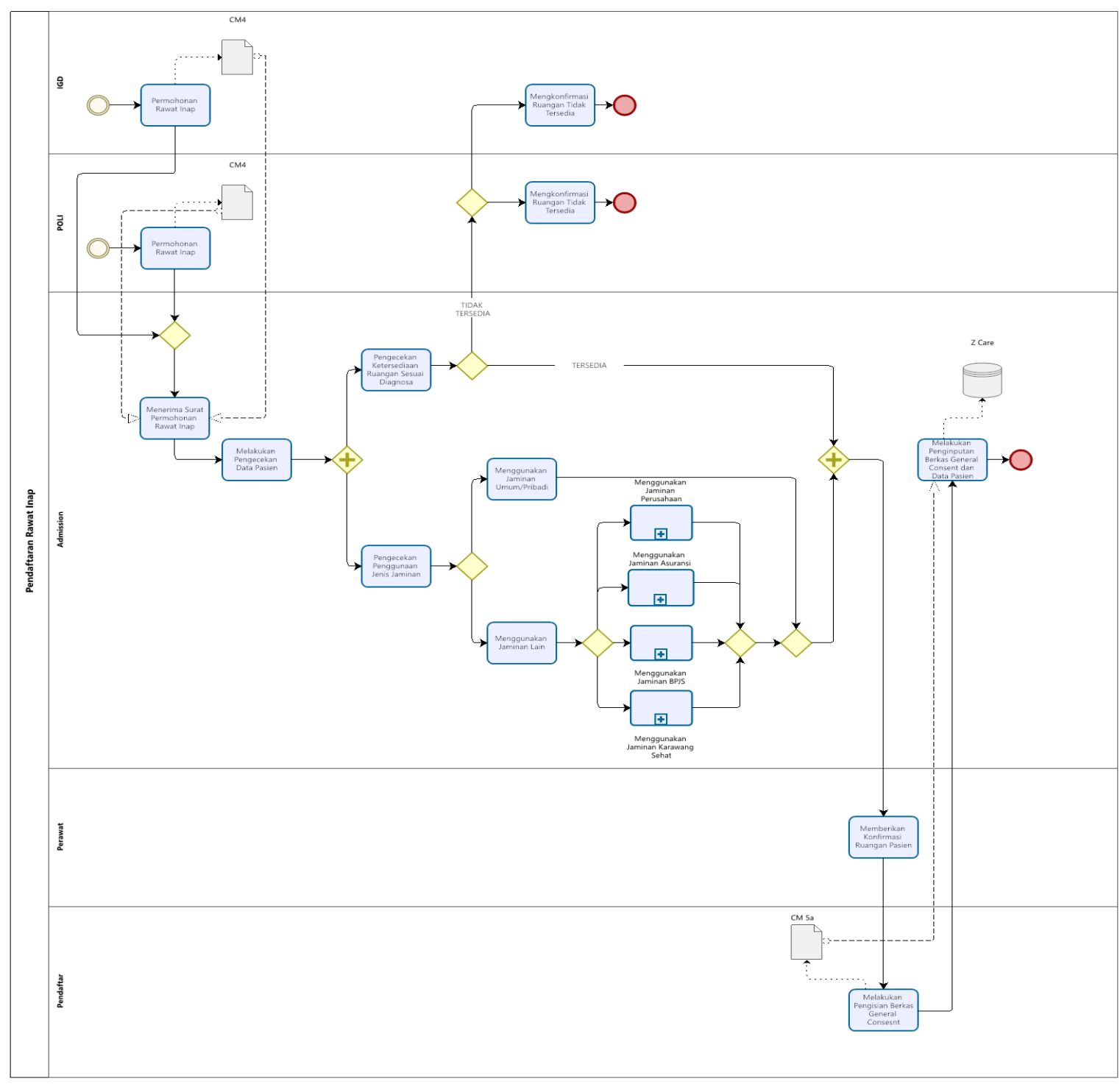

Gambar 1. Proses Bisnis Pendaftaran Rawat Inap 
Pada Gambar 1 merupakan alur proses bisnis dari pendaftaran rawat inap pada RS Dewi Sri. Dalam proses pendaftaran rawat inap melibatkan beberapa aktor yaitu bagian IGD, bagian Poli, Admission, Perawat dan Pendaftar itu sendiri. Untuk melakukan pendaftaran rawat inap, pasien harus sudah melakukan checkup pada rumah sakit terlebih dahulu dan mendapatkan rujukan untuk dilakukan rawat inap, bagian IGD dan Poli membuat permohonan rawat inap, selanjutnya permohonan rawat inap diterima oleh admission, admission akan melakukan pengecekan data pasien, setelah dilakukan pengecekan data pasien, dilakukan pengecekan penggunaan jaminan kesehatan yang akan digunakan dan pengecekan ketersediaan kamar apakah kamar tersedia atau tidak, jika tidak tersedia admission akan memberitahukan kepada bagian IGD dan Poli, jika kamar tersedia maka admission memberikan informasi kepada perawat bahwa kamar rawat inap tersedia, selanjutnya perawat akan memberitahukan kepada pendaftar, pendaftar melakukan pengisian berkas general consent yang akan diberikan pada admission untuk dilakukan proses pendaftaran, selesai.

\section{Kesimpulan}

Proses bisnis adalah serangkaian kegiatan yang saling terkait untuk mencapai tujuan bisnis tertentu. Kegiatan ini diselesaikan secara berurutan atau paralel oleh orang-orang atau sistem di dalam dan di luar organisasi. Berdasarkan hal tersebut peneliti memanfaatkan pemodelan proses bisnis pendaftaran rawat inap Rumah Sakit Dewi Sri (RSDS) untuk mendefinisikan dan menginisiasi manajemen proses bisnis dalam rangka perbaikan dan penyempurnaan proses bisnis untuk inovasi atau keunggulan kompetitif perusahaan. Hasil pengumpulan data dapat diidentifikasi bahwa pada proses transaksi penjualan terdapat beberapa sub proses diantaranya penggunaan jaminan BPJS, Asuransi, Perusahaan, dan Karawang Sehat.

\section{References}

Dewi, L. P., Indahyanti, U., Informatika, J. T., Industri, F. T., \& Petra, U. K. (n.d.). PEMODELAN PROSES BISNIS MENGGUNAKAN ACTIVITY DIAGRAM UML DAN BPMN ( STUDI KASUS FRS ONLINE ).

Galih Mardika, A., \& Kartadie, R. (2019). Mengatur Kelembaban Tanah Menggunakan Sensor Kelembaban Tanah yl-69 Berbasis Arduino Pada Media Tanam Pohon Gaharu. JOEICT (Jurnal of Education and Information Communication Technology), 03(02), 130-140.

Handayani, I., Dewanto, I. J., \& Andriani, D. (2018). Pemanfaatan RinfoForm Sebagai Media Pengumpulan Data Kinerja Dosen. Technomedia Journal, 2(2), 14-28. https://doi.org/10.33050/tmj.v2i2.321

Helmi, A. T., Aknuranda, I., \& Saputra, M. C. (2018). Analisis Dan Pemodelan Proses Bisnis Menggunakan Business Process Improvement ( BPI) Pada Lembaga Bimbingan Belajar ( Studi Kasus : Lembaga Bimbingan Belajar Prisma ). 2(10).

Leopold, H. (2013). Business Process Management. In Lecture Notes in Business Information Processing (Vol. 168). https://doi.org/10.1007/978-3-319-04175-9_1

Lestari, I., Hernawati, E., Kom, M., \& Ananda, D. (2019). APLIKASI PENGOLAHAN DATA POSYANDU BERBASIS WEB ( STUDI KASUS: POSYANDU CIPAGALO ) WEB-BASED POSYANDU DATA PROCESSING APPLICATION ( CASE STUDY : POSYANDU CIPAGALO ). 5(2), 1191-1202.

Owen, M., \& Raj, J. (2003). BPMN and Business Process Management An Introduction to the New Business Process Modeling Standard. Popkin Software. https://www.bptrends.com/publicationfiles/03-04 WP BPMN and BPM Owen-Raj.pdf

Ramdhani, M. A. (2015). PEMODELAN PROSES BISNIS SISTEM AKADEMIK MENGGUNAKAN PENDEKATAN BUSINESS PROCESS MODELLING NOTATION (BPMN) (STUDI KASUS INSTITUSI PERGURUAN TINGGI XYZ) Moch. Jurnal Informasi, VII(2), 83-93.

Rifai, Z., Bratakusuma, T., Afiana, F. N., Oktaviana, L. D., \& Yunita, I. R. (2021). Pemodelan Proses Bisnis dengan BPMN untuk Kebutuhan Implementasi ERP di CV Indococo Pasific. Jurnal Pro Bisnis, 14(2). http://ccg.co.id/blog/2017/04/28/pemodelan-proses-bisnis-dengan-bpmn/

Saputra, H. M. J., Marviainyda, D. E., Larasatu, R. A., Addaffa, M. Z. A., \& Atrinawati, L. H. (2020). Analisis Proses Bisnis pada Dinas Perdagangan Kota XYZ dengan Menggunakan Business Process Management Lifecycle. SPECTA Journal of Technology, 4(1), 71-83. https://doi.org/10.35718/specta.v4i1.181

Setiawan, E., Husin, S., \& Sumaga, M. (2019). Pemodelan Proses Bisnis Sistem Akademik Menggunakan Pendekatan Business Process Modelling Notation (BPMN). Jurnal Informasi, 2, 80-87.

Setiyani, L., Matalatta, I., \& Tjandra, E. (2021). BUSINESS PROCESS MANAGEMENT MATERIAL TRANSFER SYSTEM WAREHOUSE DEPARTMENT PT. XYZ. The 2nd International Conference on Inovations in Social 
Sciences Education and Engineering ( ICoISSEE).

Wagiu, E. B. (2018). PEMODELAN PROSES BISNIS DENGAN BPMN (STUDI KASUS: DEPARTEMEN PROCUREMENT UNIVERSITAS ADVENT INDONESIA). Jurnal TelKa, 8(1), 39-44.

www.bpmn.org. (2020). BPMN Quick Guide. http://www.bpmn.org/

Yunitarini, R., \& Hastarita, F. (2016). Pemodelan Proses Bisnis Akademik Teknik Informatika Universitas Trunojouo dengan Business Process Modelling Notation (BPMN). SimanteC, 5(2), 93-100. 